\title{
Increased endothelin-1 production in fibroblasts derived from patients with systemic sclerosis
}

\author{
Yasushi Kawaguchi, Kimihiro Suzuki, Masako Hara, Toshihiko Hidaka, Toshiaki Ishizuka, \\ Mitsuhiro Kawagoe, Haruo Nakamura
}

\begin{abstract}
Objectives-To determine whether fibroblasts from patients with systemic sclerosis (SSc) produce excessive amounts of endothelin-1 (ET-1), which is recognised as having vasoconstrictive properties and as having a potent mitogenic effect on fibroblasts

Methods-Dermal fibroblasts were removed from 11 patients with SSc and from five normal controls (NC). The assay of ET-1 protein was measured by an ELISA that used two anti-ET-1 antibodies. The gene expression of prepro ET-1 mRNA was evaluated by a reverse-transcriptase polymerase chain reaction (RT-PCR) method.

Results-Levels of ET-1 protein were significantly higher in SSc fibroblast cultures than in those of normal fibroblasts $(p<0.01)$. The expression of prepro ET-1 mRNA was also higher in SSc fibroblasts than in normal fibroblasts. The

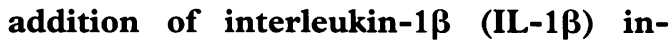
creased the production of ET-1 by fibroblasts.

Conclusion-The findings indicate that the overproduction of ET-1 is a novel abnormal function in SSc fibroblasts, and that ET-1 induced by fibroblasts may play a role in the fibrosis and Raynaud's phenomenon of SSc.
\end{abstract}

(Ann Rheum Dis 1994; 53: 506-510)

Internal Medicine,

National Defense

Medical College,

Saitama, Japan

Y Kawaguchi

K Suzuki

T Hidaka

T Ishizuka

H Nakamura

Institute of

Rheumatology,

Tokyo Women's

Medical College,

Tokyo, Japan

$M$ Hara

Department of

Internal Medicine,

Urawa Municipal

Hospital,

Saitama, Japan

M Kawagoe

Correspondence to: Dr Yasushi Kawaguchi,

First Department of Internal

Medicine

Maticine,

3-2 Namiki, Tokorazawa,

Saitama 359, Japan.

Accepted for publication

19 April 1994 Systemic sclerosis (SSc, scleroderma) is a connective tissue disease characterised mainly by fibrosis and endothelial damages. Although it is well known that Raynaud's phenomenon is an initial symptom in SSc patients, the mechanism underlying Raynaud's phenomenon remains to be clarified. Endothelin-1 (ET-1) is a vasoactive peptide isolated from the supernatant of serum free cultured endothelial cells, ${ }^{1}$ and is believed to play an important role in the regulation of blood flow in microvascular beds. ${ }^{2}$ Because of its prolonged vasoconstrictor effect, it has been suggested that ET-1 could modulate the vasospastic episodes involved in Raynaud's phenomenon. ${ }^{3}$ Recently, an increased plasma level of ET-1 has been observed in patients with Raynaud's phenomenon complicated with SSc. ${ }^{45}$ In addition, since ET-1 can also stimulate in vitro proliferation of fibroblasts, ${ }^{4}$ it is possible that it may be associated with the fibrosis in SSc.
SSc fibroblasts have been reported to be associated with cytokine production, ${ }^{6}$ growth factor production, ${ }^{78}$ proliferation, ${ }^{9}$ production of extracellular matrix components ${ }^{10-12}$ and adhesion molecule expression. ${ }^{13}{ }^{14}$ However, ET-1 production by SSc fibroblast cultures has not as yet been examined. The purpose therefore of the present study is: (1) To determine if ET-1 production by fibroblasts from SSc patients is the same as that in healthy subjects, and (2) to examine the effect of interleukin-1 $\beta$ (IL-1 $\beta$ ), which is a potent regulator of ET-1 production by endothelial cells, on ET-1 production in human dermal fibroblasts.

\section{Patients and methods}

FIBROBL_AST SOURCES AND CULTURING

Dermal fibroblasts were explanted from 11 patients with SSc (table) and from five normal controls. Following the criteria established by the American Rheumatism Association, ${ }^{15}$ six of the $11 \mathrm{SSc}$ patients were diagnosed as having diffuse SSc and the other five as having limited SSc. The explants were derived by $5 \mathrm{~mm}$ punch biopsy from affected skins of patients and dorsal forearm skin of normal controls. The control group was approximately matched for sex and age with the patient group. A lower portion of biopsied tissue was minced and placed in plastic dishes (Corning Glass Works, Corning, NY). After attachment had occurred, Dulbecco's modification of essential medium (DMEM, Flow Laboratories, McLean, VA) with $10 \%$ fetal calf serum (FCS, Flow Laboratories), 10 units $/ \mathrm{ml}$ of penicillin, and $10 \mu \mathrm{g} / \mathrm{ml}$ of streptomycin (Gibco Laboratories,

\section{Clinical characteristics of the systemic sclerosis patients}

\begin{tabular}{|c|c|c|c|c|}
\hline $\begin{array}{l}\text { Patient } \\
\text { No }\end{array}$ & Diagnosis & $\begin{array}{l}\text { Agel } \\
\text { Sex }\end{array}$ & $\begin{array}{l}\text { Duration } \\
\text { (month) }\end{array}$ & Systemic involvements \\
\hline 1 & Diffuse & $54 / \mathrm{F}$ & 12 & Pulmonary fibrosis \\
\hline 2 & Diffuse & $27 / \mathrm{F}$ & 6 & $\begin{array}{l}\text { Pulmonary fibrosis } \\
\text { Reflux esophagitis }\end{array}$ \\
\hline 3 & Diffuse & $63 / \mathrm{M}$ & 12 & Pulmonary fibrosis \\
\hline 4 & Diffuse & $57 / \mathrm{F}$ & 6 & $\begin{array}{l}\text { Pulmonary fibrosis } \\
\text { Reflux esophagitis }\end{array}$ \\
\hline 5 & Diffuse & $23 / M$ & 60 & $\begin{array}{l}\text { Pulmonary fibrosis } \\
\text { Reflux esophagitis } \\
\text { Ventricular congestive } \\
\text { Failure with arrhythmia }\end{array}$ \\
\hline 6 & Diffuse & $32 / \mathrm{F}$ & 7 & Pulmonary fibrosis \\
\hline 7 & Limited & $44 / \mathrm{F}$ & 12 & Reflux esophagitis \\
\hline 8 & Limited & $35 / \mathrm{F}$ & 6 & Reflux esophagitis \\
\hline 9 & Limited & $48 / \mathrm{F}$ & 4 & Reflux esophagitis \\
\hline 10 & Limited & $48 / \mathrm{F}$ & 12 & \\
\hline 11 & Limited & $67 / \mathrm{M}$ & 3 & $\begin{array}{l}\text { Reflux esophagitis } \\
\text { Telangiectasia }\end{array}$ \\
\hline
\end{tabular}

All patients were complicated with Raynaud's phenomenon. 
The dishes were incubated at $37^{\circ} \mathrm{C}$ in $5 \% \mathrm{CO}_{2}-$ $95 \%$ air. Fibroblasts from all biopsied subjects were rapidly frozen with $7 \%$ dimethylsulfoxide in liquid $\mathrm{N}_{2}$ and defrosted as needed. Cells in the third through fifth passages were used in this study.

ENDOTHELIAL CELL CULTURING

Human umbilical vein endothelial cells (HUVEC), isolated from one fresh human umbilical cord, were purchased from Sanko Junyaku (Tokyo, Japan). The cells were cultured in DMEM with 10\% FCS and antibiotics. Cells in the second passages were used in this study.

MEASUREMENT OF ET-1

Monolayer confluent fibroblasts or HUVEC were cultured in 24-well culture plates with ASF-301, a serum-free media ${ }^{16}$ (Ajinomoto, Tokyo, Japan) in the presence or absence of recombinant interleukin-1 $\beta$ (IL-1 $\beta$, Otsuka Pharmaceutical, Tokushima, Japan). ET-1 was measured in the supernatants of fibroblast cultures using an ELISA kit (Takeda Chemical Industries, Osaka, Japan) developed by Suzuki et $a l .{ }^{17}$ This assay uses two antibodies which recognise different epitopes of the human ET- 1 and is sensitive to as little as $0.4 \mathrm{pg} / \mathrm{ml}$. The data were adjusted in accordance with cell counts after the various incubation periods.

ISOLATION AND ANALYSIS OF TOTAL RNA FROM HUMAN SKIN FIBROBLASTS

For isolation of total RNA, six SSc and three normal fibroblast cultures were allowed to reach confluency in $100 \mathrm{~mm}$ plastic culture dishes, after the medium was replaced with ASF-301. Seventy two hours later, the total RNA was isolated by using RNA $\mathrm{Zol}^{\mathrm{TM}}$ (Biotex Laboratories, Houston, TX). Analysis of gene expression at the RNA level was performed using a GeneAmp RNA PCR kit (Perkin Elmer Cetus, Norwalk, CT). Briefly, total RNA samples $(1 \mu \mathrm{g})$ were incubated at $42^{\circ} \mathrm{C}$ for 15 minutes in reverse transcription (RT) reaction mixture containing $50 \mathrm{U}$ of Moloney murine leukaemia virus reverse transcriptase. After the RT reaction, the products were held at $95^{\circ} \mathrm{C}$ for 5 minutes. DNA amplification by polymerase chain reaction (PCR) was performed in PCR buffer containing $0.15 \mu \mathrm{M}$ primers (sense and antisense) and $2.5 \mathrm{U}$ AmpliTaq DNA polymerase. The sequences of the sense and antisense primers for prepro ET-1 are 5'-TGGCTTGCCAAGGAGCTCCA-3' and 5'-CTCCAAGGCTCTCTTGGACC-3', respectively. Amplification of the same RNA with $\beta$-actin primers confirmed that equal amounts of RNA were reverse-transcribed. The sequences of the primers for $\beta$-actin are 5'-AAGAGAGGCATCCTCACCCT-3' and 5'-TACATGGCTGGGGTGTTGAA-3', respectively. The mixture was amplified with the Perkin-Elmer Cetus thermal cycler. The amplification profile was 25,30 , or 35 cycles of denaturation at $95^{\circ} \mathrm{C}$ for 1 minute primer annealing and extension at $60^{\circ} \mathrm{C}$ for 1 minute. At the end of each cycle the reaction was continued with an extension incubation at $60^{\circ} \mathrm{C}$ for 7 minutes. The PCR products were electrophoresed in 3\% NuSieve/1\% SeaKem agarose gel stained with ethidium bromide and visualised under ultraviolet light.

STATISTICAL ANALYSIS

All results were expressed as mean (SD). Student's $t$ test was used to compare the differences between the means of the groups. A $p$ value equal to or less than 0.05 was regarded as significant.

\section{Results}

ET-1 PRODUCTION BY SSC AND NORMAL FIBROBLAST CULTURES AND ENDOTHELIAL CELL CULTURE

Examination of the kinetics of ET-1 production by fibroblast monolayer cultures (3-5 passages) revealed that ET-1 production increased more rapidly and achieved higher levels in patients with SSc than in healthy controls. Data from 11 patients with SSc and five normal controls (NC), representing the levels of ET-1 production in the supernatants after 12, 24, 48 and 72 hours of culturing, are shown in figure $1 \mathrm{~A}$.

The mean (SD) ET-1 production levels at 24 hours of culturing were significantly higher in fibroblast cultures from the $11 \mathrm{SSc}$ patients than in cultures from five normal controls [8.4 $(4.4)$ versus $1.6(0.2) \mathrm{pg} / 10^{5}$ cells, $\left.\mathrm{p}<0.01\right]$ (fig 1B). The $11 \mathrm{SSc}$ cultures stemmed from five patients with limited SSc and six with diffuse SSc; there was no significant difference in mean ET-1 production levels between the two groups.

In addition, ET-1 production by human umbilical vein endothelial cell (HUVEC) was examined using the same methods. The kinetics study of ET-1 production indicated that ET-1 production increased more rapidly and achieved higher levels (approximately 25-fold) in HUVEC than in human normal skin fibroblasts (fig 2).

PREPRO ET-1 MRNA EXPRESSION IN SSC FIBROBLASTS AND NORMAL CONTROLS Fibroblasts from six SSc patients (three diffuse and three limited SSc) and three normal controls (NC) expressed prepro ET-1 mRNA constitutively. The levels of ET-1 mRNA in SSc fibroblasts were higher than those in NC at all cycles of amplification, whereas the levels of $\beta$-actin mRNA in SSc fibroblasts were approximately equal to those in NC (fig 3). There was no difference between fibroblasts derived from diffuse and limited SSc patients.

EFFECT OF IL- $1 \beta$ ON ET-1 PRODUCTION IN FIBROBLASTS

ET-1 production by fibroblasts from five normal controls and from five patients with 

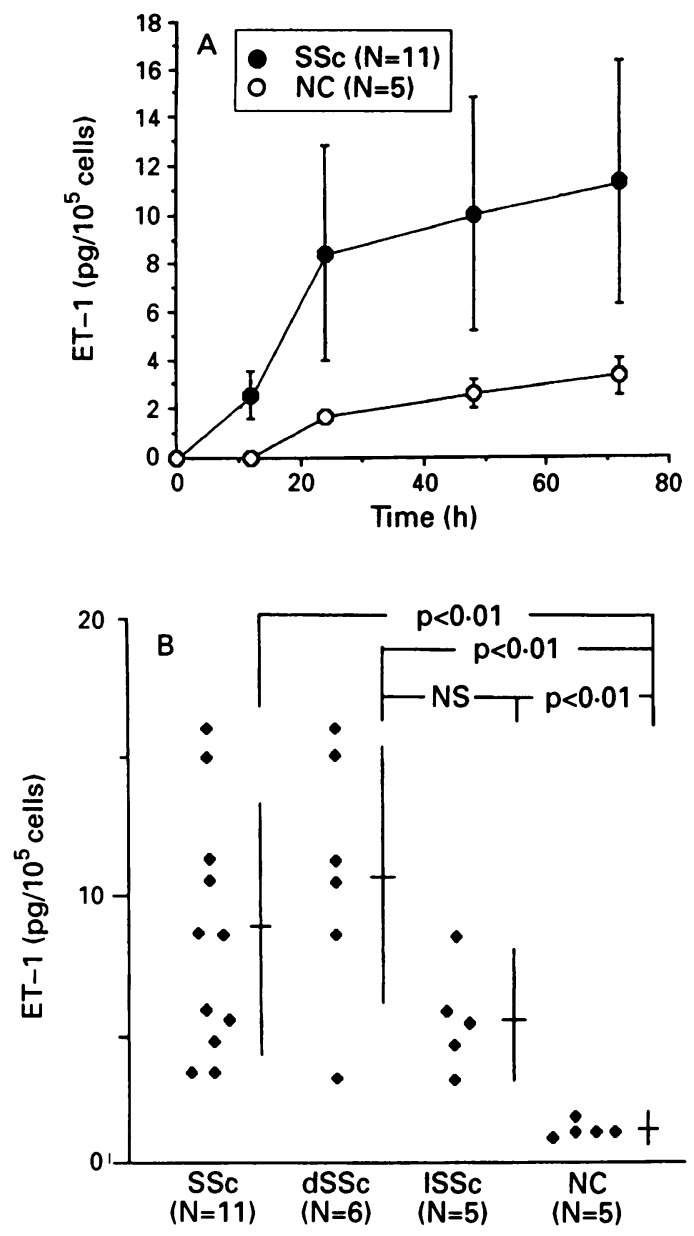

Figure 1 (A) Kinetics of ET-1 production in SSc and normal fibroblasts. At 0 time, confluent fibroblast cultures from 11 SSc patients and five normal healthy individuals (NC) were placed in serum-free media. The supernatants were collected at the indicated times and assayed by an ELISA kit, as described in Patients and methods. The results represent the means (SD) of triplicate assays performed on 11 SSc patients and five NC; (B) Levels of ET-1 production in SSc and normal fibroblasts. Fibroblast cultures from 6 diffuse SSc patients (dSSc), five limited $S S c$ patients ( SSSc) and five normal healthy individuals (NC) were prepared. At the time zero, confluent fibroblast cultures were placed in serum-free media. After the cultures were incubated for an additional 24 hours, the supernatants were collected and assayed by an ELISA kit, as described in Patients and methods. The results represent the means of triplicate assays performed on 11 SSc patients and five NC. $N S=$ not significant .

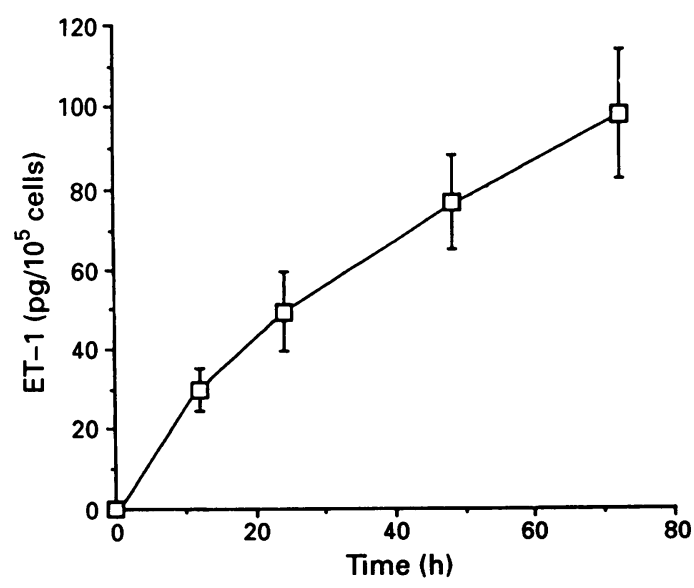

Figure 2 ET-1 production in human umbilical vein endothelial cell (HUVEC). HUVEC were placed in serum free media. The supernatants were collected at the indicated times and assayed by an ELISA kit, as described in

Patients and methods. The results represent the means (SD) of triplicate assays.
SSc was enhanced by the presence of IL-1 $\beta$ in a dose-dependent manner (fig 4). At IL-1 $\beta$ concentrations of 1 and $10 \mathrm{nM}$ (normal controls) or $10 \mathrm{nM}$ (SSc patients), ET-1 production was significantly higher $(\mathrm{p}<0.01)$ than at spontaneous levels.

\section{Discussion}

The results of the present study demonstrate that the amount of ET-1 produced by SSc fibroblasts in serum-free media is much greater than that by normal controls in vitro (fig 1). Although it has been reported that normal fibroblasts were able to produce ET $-1,{ }^{18}$ the present study is the first attempt to evaluate the amount of ET-1 produced by SSc fibroblasts. It is possible that ET-1 may mediate the vasoconstrictive events of Raynaud's phenomenon because of its prolonged vasoconstrictor effect. ${ }^{2}$ In fact, several reports indicate that the plasma level of endothelin is increased in the patients with Raynaud's phenomenon complicated with SSc. ${ }^{4}$ These reports suggest that the increased levels of endothelin might result from endothelial cell damage. However, there is no evidence to date that endothelial cells in patients with SSc can overproduce ET-1 protein in vitro or in vivo. In our study it seems clear that ET-1 derived from SSc fibroblasts is augmented and that the increased levels of ET-1 could have vasoconstrictor effects, irrespective of whether or not endothelial cell damage exists in SSc patients.

To clarify the relationship between ET-1 production and the extent of fibrosis, we examined the difference in ET-1 production between diffuse and limited SSc. As indicated in the table, all diffuse SSc patients were complicated with pulmonary fibrosis. The mean (SD) levels of ET-1 in diffuse SSc were higher than those in limited SSc $[10.7(4.8) v$ $5 \cdot 7$ (1.9)], although there was no significant difference between the two groups. This result may support the hypothesis that fibroblasts derived from SSc patients with extensive fibrosis could constitutively produce higher levels of ET-1. To evaluate this hypothesis, further studies are required.

The largest source of ET-1 seems to be the endothelial cells. More specifically, the level of ET-1 production in human umbilical vein endothlial cells (HUVEC) in vitro is reportedly approximately 20-100 times more than that in normal human fibroblast cells. ${ }^{19} 20$ We also examined the level of ET-1 produced by HUVEC in serum-free media and found that our data agreed with the previous reports. The increased level of ET-1 production in SSc fibroblasts found in the present study was lower than the spontaneous level of ET-1 production in normal HUVEC. This fact suggests that the increased serum level of ET-1 in SSc patients is little affected by the overproduction of ET-1 in SSc fibroblasts. In sclerodermatous skin, however, there is little doubt that ET-1, which is constitutively overproduced by SSc fibroblasts, can stimulate the fibroblasts themselves as well as endothelial and vascular smooth muscle cells in an 

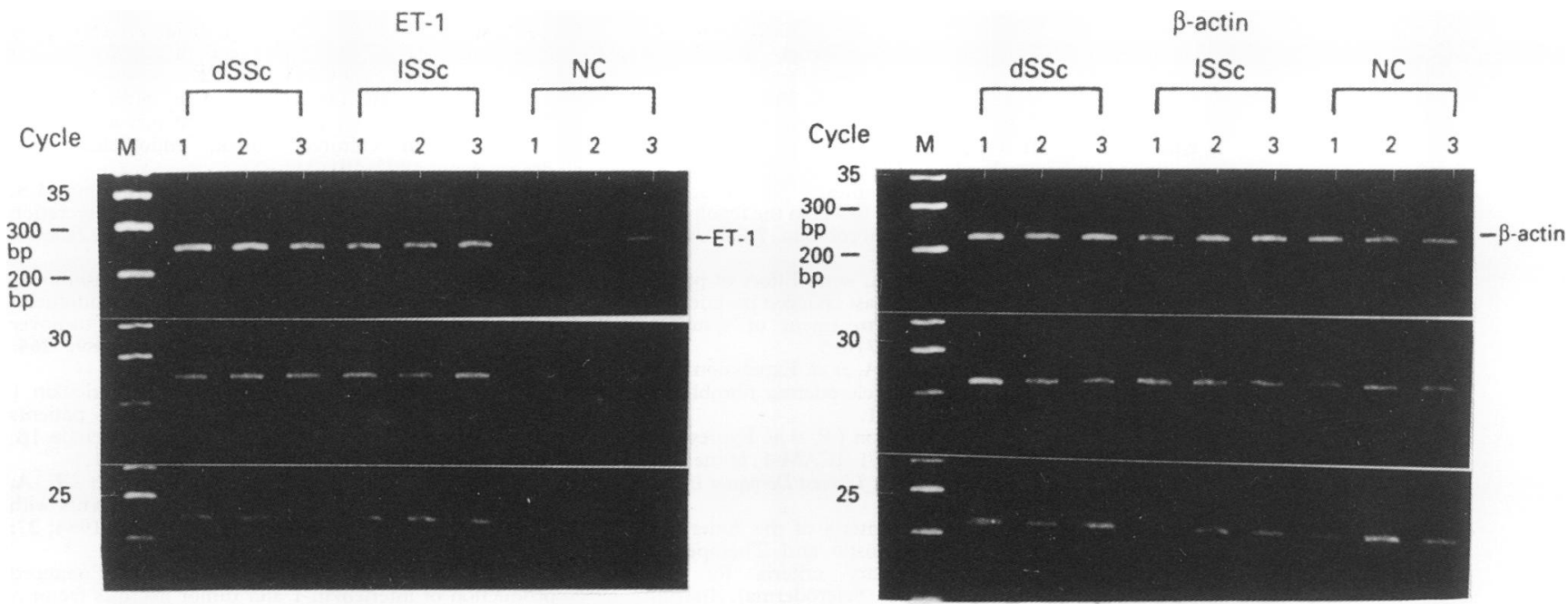

Figure 3 Expression of prepro ET-1 mRNA in SSc and normal fibroblasts. Fibroblasts from three diffuse SSc (dSSc), three limited SSc (ISSc) and three normal subjects (NC) were cultured with serum-free media for 72 hours. Total RNA were extracted by the RNA Zol, and an RT-PCR analysis was performed as described in Patients and Methods. Amplified fragments were detected at 25, 30, or 35 cycles of PCR at expected sizes by ethidium bromide staining (prepro ET-1: $248 \mathrm{bp} ; \beta$-actin: $218 \mathrm{bp}$ ). Amplification of $\beta$-actin was performed to ensure equal recovery of RNA. Lane M is the DNA molecular weight marker (100 bp DNA Ladder, GIBCO BRL, Gaithersburg, MD).

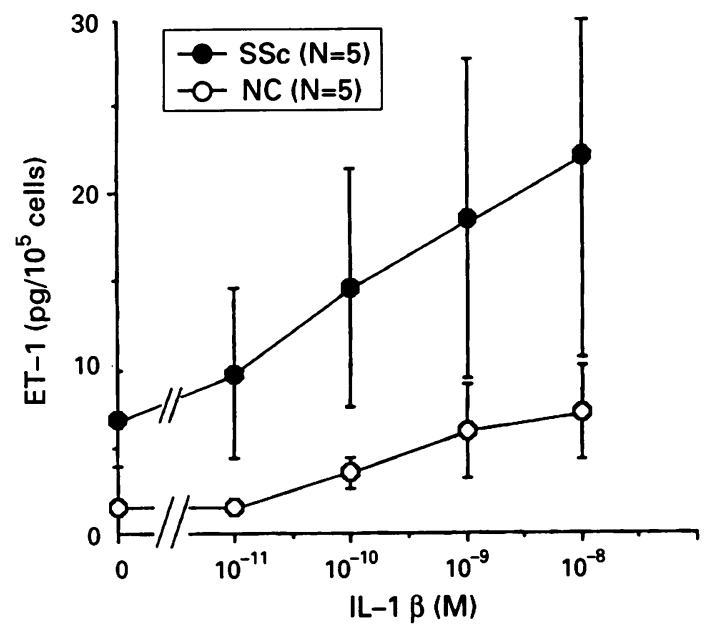

Figure 4 Effect of IL-1 $1 \beta$ on ET-1 production in SSc and normal fibroblasts. Fibroblasts from five SSc and five normal controls (NC) were cultured with serum-free media in the presence or absence of $I L-1 \beta\left(0,10^{-11}-10^{-8} M\right)$ for 24 hours. The supernatants were collected and ET-1 production was measured by an ELISA kit, as described in Patients and methods.

$\star \star p<0.01$ compared with the unstimulated fibroblast cultures.

autocrine or paracrine manner. In addition, several studies revealed that ET-1 could stimulate proliferation and collagen production in normal fibroblasts, mainly through activation of protein kinase $C$ in the fibroblasts. ${ }^{41}$ These data suggest that the overproduction of ET-1 offers a partial explanation for the excessive collagen production of SSc fibroblasts.

Another result in the present study is the finding that IL-1 $\beta$ can augment the production of ET-1 in human fibroblasts. In an earlier report, ${ }^{22}$ SSc fibroblasts were shown to overrespond to IL-1 $\beta$. As expected therefore the levels of ET-1 production induced by IL-1 $\beta$ were higher in SSc fibroblast cultures than in those from normal subjects (fig 4).

Mononuclear cell infiltration is reportedly prominent in early sclerodermatous skin ${ }^{23}$ and peripheral mononuclear cells form SSc patients produce high levels of IL- $1 \beta{ }^{24}$ These observations strongly suggest that SSc fibroblasts may be exposed to IL-1 $\beta$ in vivo. Thus far it seems reasonable to hypothesise that IL-1 $\beta$ may stimulate ET- 1 production in SSc fibroblasts in vivo, but the mechanisms whereby increased ET-1 production can be prolonged in SSc fibroblast culture (serum-free media) in vitro remain unknown.

Taken together, our results show that the production of ET-1 in SSc fibroblasts is constitutive and augmented, and that the increased production of ET-1 might be implicated in the pathogenesis of Raynaud's phenomenon and the fibrosis in SSc. At present, studies of endothelin receptor antagonists are in progress as a result of a pharmacological approach to treating vasoconstrictive and vasospastic diseases. ${ }^{25}{ }^{26} \mathrm{We}$ expect that in the near future an endothelin receptor antagonist will be a novel valid strategy for the treatment of patients with SSc.

We are grateful to Takeda Chemical Industries, (Osaka, Japan) for the gift of the Endothelin-1 ELISA kit.

1 Yanagisawa M, Kurihara H, Kimura S, et al. A novel potent vasoconstrictor peptide produced by vascular endothelial cells. Nature (Lond) 1988; 332: 411-5.

2 Brain S D, Tippins J R, Williams T J. Endothelin induces potent microvascular constriction. Br f Pharmacol 1988; 95: $1005-7$.

3 Zamora M R, O'Brien R F, Rutherford R B, Weil J V. Serum endothelin-1 concentrations and cold provocation in primary Raynaud's phenomenon. Lancet 1990; 336: primary

4 Kahaleh $M$ B. Endothelin, an endothelial-dependent vasoconstrictor in scleroderma. Arthritis Rheum 1991; 34 978-83.

5 Yamane K, Kashiwagi H, Suzuki N, et al. Elevated plasma levels of endothelin-1 in systemic sclerosis. Arthritis Rheum 1991; 34: 243-4.

6 Feghali C A, Bost K L, Boulware D W, Levy L S. Mechanisms of pathogenesis in scleroderma. Overproduction of interleukin 6 by fibroblasts cultured from affected skin sites of patients with scleroderma. f Rheumatol 1992; 19: 1207-1.

Yamakage A, Kikuchi K, Smith E A, LeRoy E C, Trojanowska $M$. Selective upregulation of plateletderived growth factor $\alpha$ receptors by transforming growth factor $\beta$ in scleroderma fibroblasts. $\mathcal{F}$ Exp Med 1992; 175: $1227-34$

8 Kulozik M, Hogg A, Lankat-Buttgereit B, Kreig T. Colocalization of transforming growth factor $\beta 2$ with $\alpha 1$ (I) procollagen mRNA in tissue sections of patients with systemic sclerosis. $\mathcal{f}$ Clin Invest 1990; 86: 917-22. 
9 Trojanowska M, Wu L, LeRoy EC. Elevated expression of c-myc proto-oncogene in scleroderma fibroblasts. c-myc proto-oncogene
Oncogene 1988; 3: 477-81

10 Jimenez S A, Feldman G, Bashey R I, Bienkowski R, Rosenbloom J. Co-ordinate increase in the expression of type I and type III collagen genes in progressive systemic sclerosis fibroblasts. Biochem f 1986; 237: 837-43.

11 LeRoy E C. Increased collagen synthesis by scleroderma skin fibroblasts in vitro. A possible defect in the regulation or activation of the scleroderma fibroblasts. $\mathcal{F}$ Clin Invest 1974; 54: 880-89.

12 Kawaguchi Y, Harigai M, Kitani A, et al. Effect of prolyl 4-hydroxylase inhibitor on fibroblast collagen production in vitro: an approach to the treatment of systemic in vitro: an approach to the treatment

13 Abraham D, Lupoli S, McWhirter A, et al. Expression and function of surface antigen on scleroderma fibroblasts. Arthritis Rheum 1991; 34: 1164-71.

14 Majewski S, Hunzelmann N, Johnson J P, et al. Expression of intercellular adhesion molecule-1 (ICAM-1) in the skin of patients with systemic sclerosis. F Invest Dermatol 1991; 97: $667-71$.

15 Subcommittee for Scleroderma Criteria of the American Rheumatism Association Diagnostic and Therapeutic Criteria Committee: Preliminary crieria for classification of systemic sclerosis (Scleroderma). Arthritis classification of systemic

16 Murata $M$, Eto $Y$, Shibai $H$. Large-scale production of erythroid differentiation factor (EDF) by gene engineering Chinese hamster ovary $(\mathrm{CHO})$ cells in suspension culture. F Ferment Technol 1988; 66: 501-7.

17 Suzuki N, Matsumoto H, Kitada C, Masaki T, Fujino M A sensitive sandwich-enzyme immunoassay for human endothelin. F Immunol Mcthods 1989; 118: 245-50.
18 Zeballos G A, An S, Wu J M. Endothelin-1 secretion by human fibroblasts in culture: effects of cell density and IFN-3. Biochem Int 1991; 25: 845-52.

19 Horio $T$, Kohno M, Yasunari K, et al. Stimulation of endothelin-1 release by low density and very low density lipoproteins in cultured human endothelial cells. Atherosclerosis 1993; 101: 185-90.

20 Wang D J, Tang C C, Wung B S, Chen $\mathrm{H} \mathrm{H}$, Hung M S, Wang J J. Cyclic strain increases endothelin-1 secretion and gene expression in human endothelial cells. Biochem Biophys Res Commun 1993; 195: 1050-6.

21 Takuwa N, Takuwa Y, Yanagisawa $M$, Yamashita K, Masaki T. A novel vasoactive peptide endothelin stimulates mitogenesis through inositol lipid turnover in Swiss 3T3 fibroblasts. I Biol Chem 1989; 264: $7856-61$.

22 Kawaguchi Y, Harigai M, Suzuki K, et al. Interleukin 1 receptor on fibroblasts from systemic sclerosis patients induces excessive functional responses to interleukin $1 \beta$. Biochem Biophys Res Commun 1993; 190: 154-61.

23 Roumm A D, Whiteside T L, Medsger Jr T A, Rodnan G P. Lymphocytes in the skin of patients with progressive systemic sclerosis. Arthritis Rheum 1984; 27: $645-53$.

24 Umehara H, Kumagai S, Murakami M, et al. Enhanced production of interleukin-1 and tumor necrosis factor $\alpha$ by cultured peripheral blood monocytes from patients with scleroderma. Arthritis Rheum 1990; 33: 893-7.

25 Ihara M, Noguchi K, Saeki T, et al. Biological profiles of highly potent novel endothelin antagonists selective for the $\mathrm{ET}_{\mathrm{A}}$ receptor. Life $S_{c i} 1991 ; \mathbf{5 0 :} 247-55$.

26 Clozel M, Breu V, Burri K, et al. Pathophysiological role of endothelin revealed by the first orally active endothelin receptor antagonist. Nature 1993; 365: 759-61. 